NASA Technical Memorandum 107247

\title{
Oscillating Cascade Aerodynamics at Large Mean Incidence
}

Daniel H. Buffum

Lewis Research Center

Cleveland, Ohio

Vincent R. Capece and Aaron J. King

University of California

Davis, California

Yehia M. EL-Aini

Pratt \& Whitney

West Palm Beach, Florida

Prepared for the

41st Gas Turbine and Aeroengine Congress

sponsored by the International Gas Turbine Institute of

the American Society of Mechanical Engineers

Birmingham, United Kingdom, June 10-13, 1996

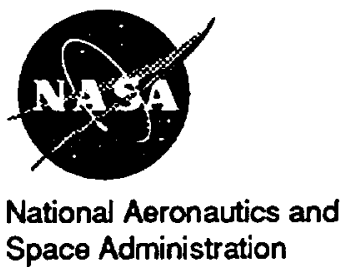





\title{
Oscillating Cascade Aerodynamics at Large Mean Incidence
}

\author{
Daniel H. Buffum \\ NASA Lewis Research Center \\ Cleveland, Ohio U.S.A \\ Vincent R. Capece and Aaron J. King \\ Department of Mechanical \& Aeronautical Engineering \\ University of California \\ Davis, California U.S.A \\ Yehia M. EL-Aini \\ Pratt \& Whitney \\ West Palm Beach, Florida U.S.A
}

\begin{abstract}
The aerodynamics of a cascade of airfoils oscillating in torsion about the midchord is investigated experimentally at a large mean incidence angle and, for reference, at a low mean incidence angle. The aiffoil section is representative of a modern, low aspect ratio, fan blade tip section. Time-dependent airfoil surface pressure measurements were made for reduced frequencies of up to 1.2 for out-of-phase oscillations at a Mach number of 0.5 and chordal incidence angles of $0^{\circ}$ and $10^{\circ}$; the Reynolds number was $0.9 \times 10^{6}$. For the $10^{\circ}$ chordal incidence angle, a separation bubble formed at the leading edge of the suction surface. The separated flow field was found to have a dramatic effect on the chordwise distribution of the unsteady pressure. In this region, substantial deviations from the attached flow data were found with the deviations becoming less apparent in the aft region of the airfoil for all reduced frequencies. In particular, near the leading edge the separated flow had a strong destabilizing influence while the attached flow had a strong stabilizing influence.
\end{abstract}

\section{NOMENCLATURE}

C blade chord length

$C_{m} \quad$ first harmonic unsteady aerodynamic moment

coefficient, Eq. 4

$\overline{C_{p}} \quad$ steady pressure coefficient, $\left(p_{\text {in }}-p\right) /\left(p V^{2}\right)$

$C_{p} \quad$ first harmonic unsteady pressure coefficient, $p_{1} / \rho V^{2} \alpha_{1}$

Im Imaginary part

$k$ reduced frequency, $\omega C / V$

$M \quad$ inlet mach number

$n \quad$ airfoil number $0, \pm 1, \ldots \pm 4$

\begin{tabular}{|c|c|}
\hline$p_{\text {in }}$ & cascade mean inlet pressure \\
\hline$P_{e x}$ & cascade mean exit pressure \\
\hline$p$ & mean pressure (zeroth harmonic) \\
\hline$p_{1}$ & first harmonic unsteady pressure \\
\hline $\operatorname{Re}$ & real part \\
\hline $\operatorname{Re}_{c}$ & Reynolds number, $\rho V C / \mu$ \\
\hline $\mathrm{R}_{\mathrm{p}}$ & cascade pressure ratio, $p_{\text {ex }} / p_{\text {in }}$ \\
\hline $\mathbf{S}$ & blade spacing \\
\hline$t_{\max }$ & maximum blade thickness \\
\hline V & inlet velocity \\
\hline $\mathrm{x}$ & chordal distance \\
\hline$x_{\max }$ & position of maximum blade thickness \\
\hline$x_{p}$ & pitching axis locations \\
\hline$\alpha$ & mean incidence relative to the airfoil chord line \\
\hline$\alpha_{1}$ & amplitude of torsional oscillation; $\alpha_{1}=0.0209$ radian \\
\hline$\beta$ & interblade phase angle \\
\hline$\gamma$ & stagger angle \\
\hline$\theta^{*}$ & leading edge camber angle \\
\hline$\mu$ & dynamic viscosity at cascade inlet \\
\hline$P$ & density at cascade inlet \\
\hline$\omega$ & frequency of oscillation \\
\hline
\end{tabular}




\section{INTRODUCTION}

Subsonic/transonic stall flutter continues to be a problem in the development of fan and compressor blades for advanced military and commercial aircraft gas turbine engines. As schematically depicted in Fig. 1, this type of flutter occurs at part speed where the blade incidence angle is quite large and the inlet relative Mach number is transonic; this type of flutter typically occurs in the first torsion mode. Due to the large incidence angles, viscous effects are significant for this type of flutter. While considerable effort has been devoted to the development of unsteady aerodynamic models for flutter, accurate predictions of stall flutter have remained elusive. As a result, current stall flutter prediction systems rely on purely empirical correlations of flutter boundaries based on previous rig and engine testing, simplified separation models, or semi-empirical methods (EL-Aini and Capece, 1995).

To improve stall flutter predictions, experimental data are required. Unfortunately, only a very limited quantity of unsteady aerodynamic data exist at large mean incidence angles to verify and direct refinements to these models. In fact, the significant effects of unsteady separated flow at realistic reduced frequency values have not been adequately addressed experimentally for turbomachinery.

Previous investigations have, at best, been only partially successful at obtaining the data necessary to improve stall flutter prediction capabilities. For example, Carta and St. Hilaire (1979) and Carta (1983), using a linear compressor cascade in which NACA 65 series airfoils were harmonically oscillated in torsion, measured the resulting unsteady surface pressure distributions along the chord of the airfoils. These studies, at reduced frequencies (based on chord) less than 0.4 , investigated the effects of steady blade loading and interblade phase angle on the unsteady aerodynamics. This investigation showed a decrease in aerodynamic damping (stability) with increasing incidence angle even though steady flow suction surface separation was not apparent. While the interblade phase angle values were within the range of interest for turbomachines, the reduced frequency values and Mach number were low for advanced fan and compressor stall flutter.

Széchényi and Finas (1981a) and Széchényi and Girault (1981b) (the fifth standard configuration in Bölcs and Fransson (1986)) harmonically oscillated in torsion a symmetrical airfoil in a linear compressor cascade. They obtained unsteady aerodynamic data over a range of Mach numbers, reduced frequencies, and incidence angles, including partially and fully separated flow. Experimental results for 0.5 Mach number have indicated negative aerodynamic damping (instability) for incidence angles greater than $8^{\circ}$ for a reduced frequency of 0.74 . In this experiment only one blade was oscillated. Hence, the experimental data does not explicitly account for the effects of interblade phase angle. Instead, the unsteady aerodynamic coefficients correspond to the influence of the oscillation of the reference blade on itself when all other blades in the cascade are fixed.

These investigations point to the basic difficulty of cascade stall flutter investigations: it is extremely difficult to obtain experimental data with all of the relevant parameters simultaneously having appropriate values. Appropriate values are: (1) high subsonic or transonic mean flow, (2) large mean incidence angles that include separated flow, and (3) reduced frequency of one or greater. In addition, data for simultaneous oscillation of the airfoils at a number of different interblade phase angles is desirable.

The objective of this experimental investigation is to obtain data that are, in all respects, appropriate for advancing the state of turbomachinery stall flutter prediction capabilities. Experiments are performed that use the unique capability of the NASA Lewis Research Center Transonic Oscillating Cascade to simultaneously obtain appropriate parameter values. These experiments quantify the effects of separation and reduced frequency on the airfoil unsteady aerodynamic response.

In this paper, the aerodynamics of a cascade of airfoils executing torsion mode oscillations is investigated. The airfoil cross-section was similar to that found in the tip region of low aspect ratio fan blades. For an inlet Mach number of 0.5 , results will be presented for a low mean incidence, attached flow condition and a high mean incidence condition with leading edge separation. Reduced frequencies as high as 1.2 were attained. The low incidence data are correlated with predictions from a linearized cascade unsteady aerodynamics code.

\section{FACILITY AND INSTRUMENTATION}

\section{Oscillating Cascade}

The NASA Lewis Oscillating Cascade, Fig. 2, combines a linear cascade wind tunnel capable of inlet flow approaching Mach 1 with a high-speed airfoil drive system. The drive system imparts torsional oscillations to the cascaded airfoils at specified interblade phase angles and realistic values of reduced frequency. For facility details not discussed below, see Buffum and Fleeter (1990).

Air drawn from the atmosphere passes though honeycomb into a smooth contraction inlet section then into a constant area rectangular duct. For an inlet Mach number of 0.2 , turbulence intensity in the test section was $0.3 \%$. The duct measures $9.78 \mathrm{~cm}$ in span and $58.6 \mathrm{~cm}$ along the stagger line. Upstream of the test section, suction is applied through perforated sidewalls to reduce the boundary layer thickness. Tailboards are used to adjust the cascade exit region static pressure and also form bleed scoops which further reduce upper and lower wall boundary layer effects. Downstream of the test section, the air is expanded through a diffuser into an exhaust header. The cascade inlet may be adjusted to obtain a wide range of incidence angles.

The facility features a high-speed mechanism which may drive any or all of the airfoils in controlled torsional oscillations. For this investigation, all the airfoils were oscillated simultaneously, and the maximum reduced frequency was 1.2 (based on chord) at an inlet Mach number of 0.5 , which corresponds to a $370 \mathrm{~Hz}$ oscillation frequency. Stainless steel barrel cams, each having a six-cycle sinusoidal groove machined into its periphery, are mounted on a common rotating shaft driven by a $74.6 \mathrm{~kW}$ electric motor. A cam follower assembly, consisting of a titanium alloy connecting arm with a stainless steel button on one end, is joined on the other end to an airfoil trunnion. The button fits into the cam groove, thus coupling the airfoil with the camshaft. The drive system geometry fixes the pitching amplitude to $1.2^{\circ}$. Lubrication of the cam/follower assembly 
is provided by an oil bath. The interblade phase angle is fixed by the relative positions of the cams on the drive shaft.

External to the oil bath, on the same shaft as the airfoil drive cams, is a cam used to indicate the shaft position. A proximity probe facing this reference cam produced a time-dependent voltage indicating the position of the airfoils.

The upper wall and the lower tailboard are acoustically treated. Experiments performed before acoustic treatment was installed (Buffum and Fleeter, 1993; Buffum and Fleeter, 1994) indicated that reflections of acoustic waves by the solid walls were compromising the blade-to-blade periodicity of the unsteady flow field. Thus the walls were modified to reduce acoustic wave reflections. Portions of the solid boundaries were replaced by perforated plates backed by enclosures filled with Kevlar fiber as depicted in Fig. 3. Rice (1992) provided the design parameters (plate thickness and porosity, hole diameter, enclosure depth and Kevlar density). Bleed lines were attached to the cavities to allow boundary layer suction through the perforated walls.

\section{Airfoils}

The airfoils used in this study have a cross-section similar to that found in the tip region of current low aspect ratio fan blades. The aiffoil section was designed using the Pratt \& Whitney fan and compressor aerodynamic design system, which is for flow in circular ducts. Hence, to simulate the two dimensional conditions to be encountered in the linear cascade, the airfoils were designed using a radius ratio of 0.99 . The loading levels, losses, solidity, and stagger angle are consistent with current design practice for fan blades. The airfoil cascade parameters are given in Table 1; refer to Fig. 4 for definitions of the geometry.

\section{Table 1 Airfoil and cascade parameters}

\begin{tabular}{|l|l|}
\hline Chord, $C$ & $8.89 \mathrm{~cm}$ \\
\hline Maximum thickness, $t_{\max }$ & 0.048 chord \\
\hline Location of maximum thickness, $x_{\max }$ & 0.625 chord \\
\hline Leading edge camber angle, $\theta^{*}$ & -9.5 degrees \\
\hline Number of airfoils & 9 \\
\hline Stagger angle, $\gamma$ & 60 degrees \\
\hline Solidity, $C / S$ & 1.52 \\
\hline Pitching axis & 0.5 chord \\
\hline
\end{tabular}

\section{Instrumentation}

Wall static pressure taps were used to measure the inlet and exit pressures. From these measurements, mean values were determined to provide the cascade pressure rise.

Four airfoils were instrumented with static pressure taps. Two aiffoils were instrumented with taps very near the midspan, one on the suction surface, the other on the pressure surface. As shown in Fig. 5(a), taps were clustered near the leading edge to capture the large pressure gradients there. Taps were also clustered in the 50 to $70 \%$ chord region in anticipation of shock wave impingement on the pressure surface when operating near choked flow conditions. Two additional airfoils were instrumented with pressure taps, Fig. 5(b), some of which are redundant to the midspan instrumentation shown in part (a) and others which indicate the spanwise variations in the pressure. The redundant midspan taps were used to indicate blade-to-blade periodicity of the cascade steady flow field. The spanwise taps supply information on the three-dimensionality of the flow field.

Two airfoils were instrumented with flush-mounted miniature pressure transducers. The transducers were chosen for having the following desirable characteristics: small dimensions, high frequency response and invariance of dynamic response with change in temperature. Static and dynamic calibrations were made.

Kulite Semiconductor Products miniature pressure transducers were used, each of which consists of a silicon diaphragm containing a four-arm strain gage bridge mounted over a cylindrical cavity. Slots were machined into the airfoil surfaces to allow the transducer diaphragms to be mounted flush with the airfoil surface and to serve as passages for the wire leads. Once the transducers were installed, each slot was filled and smoothed to the airfoil contour, and each transducer was coated with RTV (room-temperature-vulcanizing rubber) for improved durability and conformance with the airfoil profile. To provide isolation from airfoil strain, each transducer was potted in RTV. The pressure sensitive diameter was $0.7 \mathrm{~mm}(0.8 \%$ of the airfoil chord).

The transducers were located on the upper surface of one airfoil and the lower surface of another airfoil. There were 15 transducers per surface. The locations, the same as those of the midspan pressure taps (Fig. 5(a)), vary from 6 to $95 \%$ of chord. The transducer thickness relative to the airfoil thickness was the limiting factor in placing the transducers closest to the leading and trailing edges; at these locations, the airfoil thickness was chosen to be at least twice the transducer thickness.

Static calibration of the transducers was performed at NASA Lewis Research Center. Each blade was installed in a calibration chamber, the ambient pressure of which was controlled using a vacuum pump. The transducer electronics and the data acquisition system were identical to those used during all of the calibrations and the unsteady experiments. The response for each transducer was linear. The calibrations were repeatable - changes in sensitivities were typically less than $0.25 \%$ between calibrations.

Although the transducer specifications state that the frequency response is in excess of $100 \mathrm{kHz}$, the RTV coating is expected to reduce it. To verify the response, a resonant tube assembly similar to that used by Capece and Fleeter (1987) was used to excite the transducers with acoustic waves. The assembly consists of a $20.3 \mathrm{~cm}$ diameter, $4.6 \mathrm{~m}$ long plastic tube with a speaker mounted at one end. An instrumented airfoil was mounted at the opposite end of the tube, which was open to atmosphere. Amplified sine waves were used to drive the speaker which in turn created acoustic waves in the tube for excitation of the transducers. The resulting pressure transducer 
responses were flat to frequencies in excess of $1000 \mathrm{~Hz}$ within $\pm 2 \%$ in magnitude and \pm 3 degrees in phase.

During the experiments, the pressure transducers are subject to maximum accelerations in excess of 300 times that due to gravity. Acceleration deflects the transducer diaphragm and thus produces apparent pressure signals. Calibration was used to correct for this effect. Each blade was oscillated in a chamber with low ambient pressure $(1.2 \mathrm{kPa})$ over the range of frequencies encountered in the experiments. The mode of oscillation was identical to that used in the cascade. Through Fourier analysis of the resulting signals, the transducer responses as a function of oscillation frequency were determined. Second degree polynomial curves were found to fit the calibration data well; the calibration coefficients were used to correct the experimental data. For example, at $370 \mathrm{~Hz}$, the correction for the upper surface leading edge transducer was $2.6 \mathrm{kPa}$.

\section{DATA ACQUISITION AND ANALYSIS}

Unsteady signals from the pressure transducers and the proximity probe were recorded using a Teac XR-7000 VHS tape recorder. During tape playback, the signals were simultaneously digitized at rates typically 10 times the oscillation frequency, with 16,384 samples taken per channel. Each channel of data was divided into blocks with 1024 samples, windowed using a Hanning window, then Fourier transformed to determine the first harmonic of each block. The first harmonic of each block was referenced to the airfoil motion by subtracting from it the phase of the first hamonic motion signal of the corresponding block. Once all of the blocks from a channel were decomposed in this manner, the first harmonic block results were averaged and the complex-valued acceleration response was subtracted vectorally.

The motion of the $n$th airfoil is defined by the change in the incidence angle with time:

$$
\alpha^{n}(t)=\alpha+\alpha_{1} \operatorname{Re}[\exp (i(\omega t+n \beta))]
$$

The first harmonic unsteady pressure coefficient is defined as

$$
C_{p}(x)=\frac{p_{1}(x)}{\rho V^{2} \alpha_{1}}
$$

The pressure difference coefficient is defined to be the difference between the lower and upper surface unsteady pressure coefficients:

$$
\Delta C_{p}=\left(C_{p}\right)_{\text {tower }}-\left(C_{p}\right)_{\text {upper }}
$$

The unsteady aerodynamic moment coefficient for a flat plate airfoil is defined as

$$
C_{M}=\int_{0}^{1}\left(\frac{x_{p}}{C}-\frac{x}{C}\right) \Delta C_{p}\left(\frac{x}{C}\right) d \frac{x}{C}
$$

where $x_{p} / C=0.5$. The work done on the airfoil by the fluid per cycle of oscillation is proportional to $\operatorname{Im}\left(C_{M}\right)$, thus the sign of $\operatorname{Im}\left(C_{M}\right)$ determines the airfoil stability with $\operatorname{Im}\left(C_{M}\right)>0$ indicating instability.

\section{RESULTS}

Results will be presented for $0^{\circ}$ and $10^{\circ}$ of incidence at an inlet Mach number of 0.5 . These incidence angles are based on the cascade inlet angles relative to the airfoil chord line; upstream flow angle measurements were not made. Unsteady data will be presented for a $180^{\circ}$ interblade phase angle and reduced frequencies of $0.4,0.8$ and 1.2 .

For $\alpha=0^{\circ}$, the steady and unsteady data are correlated with two dimensional potential flow predictions; the influence of stream tube contractions was not considered in the analyses. For $\alpha=10^{\circ}$, solutions were not obtainable due to the extremely large flow gradients created by the sharp leading edge of the airfoils. The steady flow surface pressure distribution is correlated with the nonlinear full potential solver SFLOW (Hoyniak and Verdon, 1993), and the first harmonic surface pressure distribution is correlated with the linearized analysis LINFLO (Verdon and Hall, 1990). The predictions from SFLOW are used by LINFLO as the nonlinear background steady flow around which the harmonic unsteady flow solutions are formed.

The airfoil trailing edge was modified by inserting a wedge in place of the finite radius trailing edge for enforcement of the Kutta condition. This gave a trailing edge that was not a true cusp configuration. This was found to challenge the steady and unsteady computational implementations of the Kutta condition.

A 120 by $21 \mathrm{H}$-Grid was used in the computations. A localized region of the grid is illustrated in Fig. 6. This cosine distributed grid yields a large number of grid points in the leading and trailing edge regions where the flow gradients are the highest. The cascade inlet flow angle was varied until the best match was found between the steady chordwise pressure coefficient data and the predictions. This resulted in a $0.5^{\circ}$ chordal incidence angle being used in all of the predictions.

\section{Steady Aerodynamics}

For a linear cascade to be a valid simulation of a turbomachine blade row, the cascade must exhibit good passage-to-passage periodicity for the steady flow field. To verify that the cascade was periodic, airfoil surface pressure distributions were obtained at the center airfoil position (position 0 ) and the two adjacent positions (positions -1 and 1 ) in the nine airfoil cascade. The resulting airfoil surface pressure distributions for $M=0.5$ and $\alpha=0^{\circ}$ are shown in Fig. 7. The periodicity is good. Additionally, there is excellent agreement between the data and the SFLOW predictions up to about $85 \%$ chord. Aft of this location the predictions show a steep pressure gradient as the trailing edge is approached, whereas the upper surface data do not have this trend and the lower surface data have a more gradual pressure gradient. The discrepancy in the data-theory correlation in this region is attributed to the airfoil modification and viscous effects.

The $\alpha=10^{\circ}$ data are shown in Fig. 8. The periodicity is again good. Comparison of the pressure distributions in Figs. 7 and 8 shows the large differences in the mean flow fields due to incidence. At the lower incidence angle, the flow was attached and accelerating through the passage. At the higher incidence angle, the flow separated from the upper surface at the leading edge. 
Cascade pressure ratio and Reynolds number for the two steady flow conditions are given in Table 2 . The predicted pressure ratio for the low incidence flow was 0.924 .

To visualize the flow, the airfoil surface was coated with an oil-pigment mixture. At $10^{\circ}$ incidence, separation from the upper surface was evident. The largest separated region was found at midspan; there, the flow was separated from the leading edge to about $40 \%$ of chord. Near the endwalls, the separation bubble extended to about $7 \%$ of chord. Between midspan and the endwalls, the reattachment region was defined by a smooth arc.

To quantify three-dimensional effects in the steady flow, pressure taps were placed at several different spanwise locations of the blade upper surface. Despite the three-dimensional nature of the separation bubble, Fig. 9 shows that the spanwise pressure distributions are nearly constant, except very near the upper surface leading edge. There, the $17.5 \%$ span value of $\bar{C}_{p}$ is larger than the 35 and $52 \%$ of span values even though visualization showed that the flow was separated at each of those locations.

Table 2 Cascade pressure ratio and Reynolds number

\begin{tabular}{|cccc|}
\hline Mach no. & Incidence & $\begin{array}{c}\text { Pressure } \\
\text { ratio }\end{array}$ & $\begin{array}{c}\text { Reynolds } \\
\text { number }\end{array}$ \\
\hline 0.5 & $0^{\circ}$ & 0.93 & $0.9 \times 10^{6}$ \\
0.5 & $10^{\circ}$ & 1.03 & $0.9 \times 10^{6}$ \\
\hline
\end{tabular}

\section{Unsteady Aerodynamics}

Unsteady pressure data will be presented for $\alpha=0^{\circ}$ and $\alpha=10^{\circ}$ for out-of-phase oscillations $\left(\beta=180^{\circ}\right)$. The $\alpha=0^{\circ}$ data will be correlated with linearized flow analysis predictions. Comparisons between the $\alpha=0^{\circ}$ and the $\alpha=10^{\circ}$ data will be used to isolate effects of the mean flow on the unsteady aerodynamics. The effect of reduced frequency on the unsteady separated flow will also be investigated. Cascade dynamic periodicity was a primary concern; to quantify periodicity, unsteady data were obtained at the center airfoil position and the two adjacent positions in the nine airfoil cascade.

Starting with the $\alpha=0$ data, first harmonic unsteady pressure coefficients for $\beta=180^{\circ}, k=0.8$ are shown in Fig. 10. Data were taken for two passages. Referring to the schematic in Fig. 10, the lower surface data were taken at positions $O$ (the center airfoil position) and 1 ; the upper surface data were taken at positions -1 and 0 . For the $C_{p}$ values, $95 \%$ confidence intervals of $\pm 5 \%$ are estimated. For both surfaces, the data are highly periodic. The lower surface response is dominated by $\operatorname{Re}\left(C_{p}\right)$ forward of midchord. Gaps in the lower surface data at 60 and $65 \%$ of chord, along with several other missing data points, are due to transducer failures. In contrast, the upper surface response on the forward half of the airfoil is rather flat outside of an abrupt increase in both the real and imaginary parts very near the leading edge. On the aft half of the upper surface, potentially interesting trends in $\operatorname{Re}\left(C_{p}\right)$ are obscured by faulty transducers at 65 and $70 \%$ of chord.
Predictions of the chordwise distribution of $C_{p}$ are in good agreement with the $\alpha=0^{\circ}$ data in terms of magnitude and trend. The upper surface predictions illustrate exceptional agreement with the data, whereas the iower surface predictions show some deviation near the leading edge for the imaginary part and near the trailing edge for the real part starting at about $80 \%$ chord.

Changing the mean incidence angle to $10^{\circ}$ has a dramatic effect on the unsteady pressure coefficient distributions. In Fig. 11(a), while the distribution of the lower surface $\operatorname{Im}\left(C_{p}\right)$ data is quite similar to the $\alpha=0^{\circ}$ data, the $\operatorname{Re}\left(C_{p}\right)$ data reach a much smaller peak near the leading edge. To no surprise, the upper surface pressure coefficients shown in Fig. 11(b) are greatly affected by the separation; relative to the $\alpha=0^{\circ}$ data, much larger pressure fluctuations are evident over the first half of the blade with the exception of $x / C=0.06$. Despite the severely separated flc: $N$, the unsteady pressure data are highly periodic.

Airfoil upper surface pressure spectra for these two conditions are shown in Fig. 12. At low incidence, Fig. 12(a), the spectra are dominated by the response at the oscillation frequency, and only in the measurement nearest the leading edge is there a significant higher harmonic response. In contrast, the high incidence spectra, Fig. 12(b), show higher harmonic responses at all locations encompassed by the steady flow separation bubble with the first harmonic responses still dominant.

To further illustrate the mean flow effects, $\Delta C_{p}$ distributions for $\beta=180^{\circ}, k=0.8$ are shown in Fig. 13 for $\alpha=0^{\circ}$ and $\alpha=10^{\circ}$. The $\Delta C_{p}$ values were calculated using the available center airfoil data; where center airfoil data were incomplete, i.e. $x / C=0.06$, data from the neighboring airfoils were used. The trends in the unsteady loading for the two different values of mean incidence are quite different. Near the leading edge, $\operatorname{Re}\left(\Delta C_{p}\right)_{\alpha=0}$ exhibits a large negative slope. $\operatorname{Re}\left(\Delta C_{p}\right)_{\alpha=10}$. starts with positive slope near there then, moving aft, changes to negative slope. $\operatorname{Im}\left(\Delta C_{p}\right)_{a=0}$ is negative-valued near the leading edge and has positive slope, while $\operatorname{Im}\left(\Delta C_{p}\right)_{\alpha=100}$ starts out positive-valued and has negative slope. On the aft half of the airfoil, the unsteady loading is relatively small except for $\operatorname{Re}\left(\Delta C_{p}\right)_{\alpha \infty}$. It is also seen that there is good agreement between the predictions and the data for the attached flow case. However, there are some "wiggles" in the predicted $\operatorname{Re}\left(\Delta C_{p}\right)$ in the trailing edge region of this figure and in $C_{p}$ in Fig. 10. This is believed to be caused by the airfoil modification and the high pressure gradients in the steady flow solution. This will be found in all the presented unsteady surface pressure predictions.

For $k=0.4$ and $\alpha=10^{\circ}$, the cascade dynamic periodicity, presented in Fig. 14, is also good. In Fig. 15, the center airfoil $\Delta C_{p}$ data are plotted along with the corresponding data for $\alpha=0^{\circ}$ and analysis predictions. Periodicity of the low mean incidence data (not shown) was comparable to that of the high mean incidence data. Qualitatively, the differences between the $\alpha=0^{\circ}$ and $\alpha=10^{\circ}$ data are similar to the differences seen between the corresponding $k=0.8$ data The predictions show good agreement with the attached flow data.

Analogous results for $k=1.2$ are shown in Figs. 16 and 17. There are some differences in the blade-to-blade lower surface $\operatorname{Im}\left(C_{p}\right)$ data. Otherwise the periodicit ${ }_{j}$ is gcod. Differences in $\Delta C_{p}$ due to the 
incidence angle are qualitatively similar to the differences found for $k=0.4$ and $k=0.8$. However, a comparison of Figs. 17,15 and 13 shows that the magnitude of the differences in $\operatorname{Im}\left(\Delta C_{p}\right)$ due to the incidence angle increase with frequency in the separated flow region. Once again, the predictions are in good agreement with the low incidence data.

The $C_{p}$ data for the three reduced frequencies are cross-plotted in Fig. 18. The lower surface $C_{p}$ data, Fig. 18(a), increase with reduced frequency. Increasing $k$ causes relatively small changes in $\operatorname{Re}\left(C_{p}\right)_{\text {lomer }}$ near the leading edge, but the relative changes become progressively larger as the trailing edge is approached. Changes in the imaginary part are more significant. At the lowest reduced frequency, $\operatorname{Im}\left(C_{p}\right)_{\text {lowr }}$ is near zero in value at all positions. As $k$ is increased, $\operatorname{Im}\left(C_{p}\right)_{\text {lowr }}$ increases dramatically along the first $50 \%$ of chord.

The upper surface unsteady pressure distributions, Fig. 18(b), are dominated by the unsteady separated flow, the effects of which are confined to the front half of the airfoil. Changing the reduced frequency has a profound effect on the upper surface data in the separated flow region. The low frequency $k=0.4$ data are characterized by smooth, relatively gradual changes in $C_{p}$ with chordwise position. The high frequency $k=1.2$ data are prone to much more abrupt changes and peak at larger values than the low frequency data. Changes in the intermediate $k=0.8$ data are less pronounced than the $k=1.2$ data, but more so than the $k=0.4$ data.

The chordwise extent of the separation bubble appears to fall somewhere between 35 and $50 \%$ of chord depending upon the reduced frequency. At $50 \%$ of chord, the $C_{p}$ distributions for the three frequencies are nearly converged and have relatively small magnitudes. This suggests that the flow at this point is attached throughout the cycle of oscillation. At $40 \%$ of chord, the imaginary parts are approximately equal, but the real parts decrease in magnitude with increasing reduced frequency. This behavior is consistent with the expectation that the reattachment point will move less as the frequency is increased.

Due to its influence on the unsteady aerodynamic work per cycle, the imaginary part of $\Delta C_{p}$ warrants further attention. From Eq. 4 , the contribution of the pressure difference at a point $x, \Delta C_{p}(x)$, to the unsteady aerodynanic moment coefficient is proportional to $(0.5-x)$, the distance from the pitching axis. Thus to better understand the consequences of the data shown in Fig. 18, $C_{w}^{\prime} \equiv(0.5-x / C) \operatorname{Im}\left(\Delta C_{p}(x / C)\right) \quad$ vs. $x / C$, the chordwise distribution of the work per cycle, is plotted in Fig. 19. From this figure it is clear that the cascade stability is highly dependent on the behavior of $\Delta C_{p}$ near the leading edge. In that region, the $\alpha=0^{\circ} \Delta C_{p}$ distribution has a strong stabilizing effect, while the $\alpha=10^{\circ} \Delta C_{p}$ distribution has a strong destabilizing effect. For the data points nearest the leading edge, the absolute value of $C_{w}^{\prime}$ increases with increasing $k$ - the destabilizing influence of the separated flow increases with $k$. Beyond that the data cross over into regions of destabilizing influence for the low mean incidence and stabilizing influence for the high mean incidence before coalescing at the pitching point. Although the data are too sparse in the aft airfoil section to conclude much, the data at $\mathbf{8 0}$ and $90 \%$ of chord are all stabilizing. Although more data, particularly data closer to the leading edge, are needed to draw firm conclusions, these data suggest the perhaps surprising result that increasing the reduced frequency destabilizes the cascade.

\section{SUMMARY AND CONCLUSION}

A fundamental series of experiments have been conducted in the NASA Lewis Oscillating Cascade to investigate torsion mode oscillating aerodynamics for both attached and separated flow at realistic values of the reduced frequency. The airfoil cross-section was typical of those found in advanced low aspect ratio fan blades. For an inlet Mach number of 0.5 , steady and unsteady aerodynamic data were presented for low incidence attached flow and high mean incidence flow with leading edge separation. The surface unsteady pressure distributions were quantified for reduced frequencies of $0.4,0.8$, and 1.2 for an interblade phase angle of $180^{\circ}$. The steady and unsteady aerodynamic data were correlated with potential flow analysis predictions for the attached flow cases.

The analysis of these unique data and correlation with the predictions from the potential flow analyses revealed the following.

1) For $\alpha=10^{\circ}$ the flow was found to separate from the suction surface (upper surface) at the leading edge and reattach in the $40 \%$ chord region. The separation zone was found to diminish in the endwall region. However, the flow was shown to be two dimensional in the midspan region where steady and unsteady aerodynamic response of the airfoil was quantified.

2) The steady flow exhibited good passage-to-passage periodicity for both $\alpha=0^{\circ}$ and $\alpha=10^{\circ}$, thus providing a valid simulation of a turbomachine blade row.

3) Cascade dynamic periodicity was also found to be good for both the attached and separated flow conditions, thus providing a valid simulation of a turbomachine blade row undergoing torsion mode oscillations at a constant interblade phase angle.

4) Increasing the incidence angle was found to have a significant influence on the unsteady pressure distributions, particularly in the separated flow regions. In these regions, substantial deviations from the attached flow, low incidence data were found with the deviations becoming less apparent in the aft region of the airfoil.

5) Comparing the chordwise distribution of the work-per-cycle forward of midchord for separated and attached flows showed opposite trends. Near the leading edge, the separated flows had strongly destabilizing influences while the attached flows had strongly stabilizing influences. In particular, the destabilizing influence of the separated flow near the leading edge increased with reduced frequency. Before reaching $20 \%$ of chord, the separated flows became stabilizing while the attached flows became destabilizing. Aft of midchord, the differences were small.

6) Correlation of the steady, attached flow experimental data with the predictions from a nonlinear two dimensional potential flow code was good except in the trailing edge region. The discrepancy between the data and the predictions are attributed to viscous effects that are not included in the computational model and the replacement of the finite radius trailing edge with a wedge. 
7) Correlation of the attached flow experimental data with the linearized potential code first harmonic predictions was good over most of the airfoil chord for both the individual surface pressure distributions and the pressure difference distributions. The predictions captured the trend and magnitude of the unsteady pressure distributions. Differences between the data and the predictions were most prominent in the trailing edge region where the deviations in the steady flow were also influencing the unsteady predictions.

\section{ACKNOWLEDGEMENT}

Support of this research program by the NASA Lewis Research Center and Pratt \& Whitney, Government Engines \& Space Propulsion, is gratefully acknowledged. Dr. Daniel Hoyniak of Westinghouse Electric Corp. provided many helpful suggestions to improve the computational predictions. The successful completion of the experiments was enabled by excellent engineering and technical support. The engineers were W. Camperchioli, T. Jett, H. La, J. Little and V. Verhoff. The technicians were D. Costello, M. Lupica and R. Torres. Of particular importance were improvements made by Thomas Jett and Ricardo Torres which greatly reduced the down time for the frequent cascade configuration changes.

\section{References}

Bolcs, A. and Fransson, T.H., 1986, "Aeroelasticity in Turbomachines: Comparison of Theoretical and Experimental Cascade Results," Communication du Laboratoire de Thermique Appliquee et de Turbomachines, EPF-Lausanne, Switzerland, No. 13.

Buffum, D.H. and Fleeter, S., 1990, "Aerodynamics of a Linear Oscillating Cascade," NASA Technical Memorandum 103250.

Buffum, D.H. and Fleeter, S., 1993, "Wind Tunnel Wall Effects in a Linear Oscillating Cascade," ASME Journal of Turbomachinery, Vol. 115, pp. 147-156.

Buffum, D.H. and Fleeter, S., 1994, "Effect of Wind Tunnel Acoustic Modes on Linear Oscillating Cascade Aerodynamics," ASME Journal of Turbomachinery, Vol. 116, pp. 513-524.

Capece, V.R. and Fleeter, S., 1987, "Forced Response Unsteady Aerodynamics in a Multistage Compressor," Purdue University Report ME-TSPC-TR-87-12.

Carta, F.O. and St. Hilaire, A.O., 1979, "Effect of Interblade Phase Angle and Incidence Angle on Cascade Pitching Stability," ASME Paper No. 79-GT-153.

Carta, F.O., 1983, "Unsteady Aerodynamics and Gapwise Periodicity of Oscillating Cascaded Airfoils," ASME Journal of Engineering for Power, Vol. 105, pp. 565-574.

EL-Aini, Y.M. and Capece, V.R., 1995, "Stall Flutter Prediction Techniques for Fan and Compressor Blades," AlAA Paper No. ALAA-95-2652.

Hoyniak, D. and Verdon J.M., 1993, "Development of a Steady Potential Solver for Use with Linearized Unsteady Aerodynamic Analyses," Unsteady Aerodynamics, Aeroacoustics, and Aeroelasticity of Turbomachines and Propellers, Edited by H.M. Atassi, Springer-Verlag.
Rice, E.J., 1992, Private Communication, NASA Lewis Research Center, Cleveland, $\mathrm{OH}$.

Széchényi, E. and Finas, R., 1981 a, "Aeroelastic Testing in a Straight Cascade Wind Tunnel," Aeroelasticity in Turbomachines, Edited by P. Suter, Juris-Verlag, pp. 143-149.

Széchényi, E. and Girault, J.Ph., 1981b, "A Study of Compressor Blade Stall Flutter in a Straight Cascade Wind Tunnel," Aeroelasticity in Turbomachines, Edited by P. Suter, Juris-Verlag, pp. 163-169.

Verdon, J.M. and Hall, K.C., 1990, "Development of a Linearized Unsteady Aerodynamic Analysis for Cascade Gust Response Predictions," NASA Contractor Report NAS3-25425. 


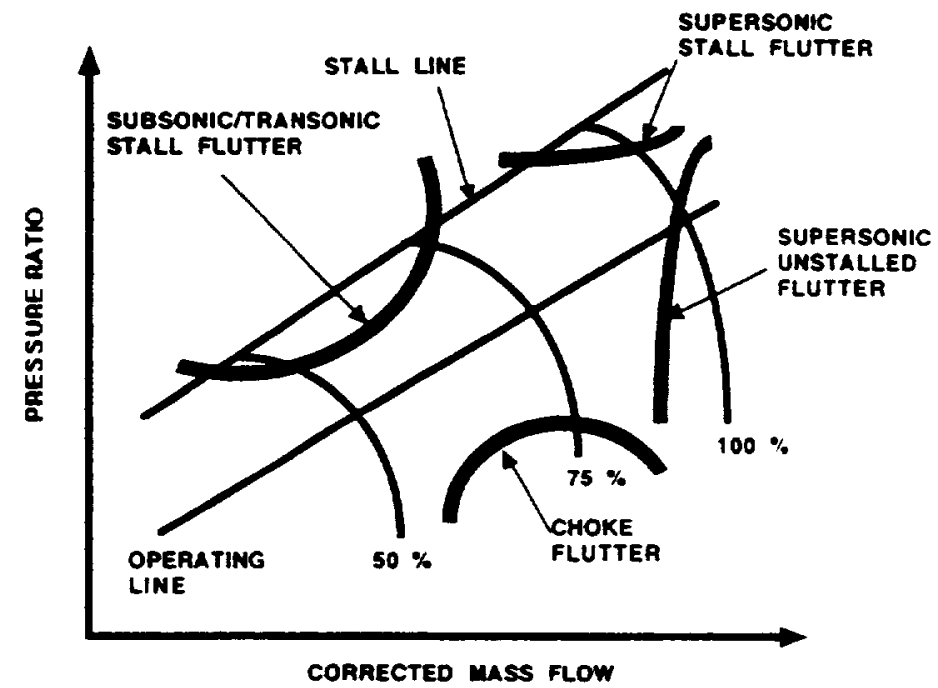

Fig.1 Compressor performance map showing flutter boundaries

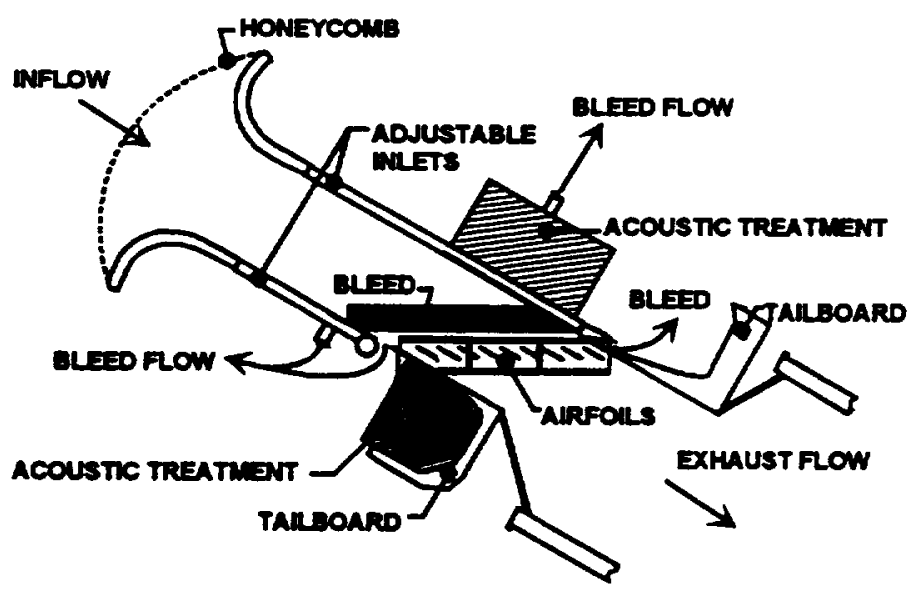

Fig. 2 NASA Lewis Oscillating Cascade

Fecleare beight, $h=35.5 \mathrm{em}$ Pinte thelocen $-1.6 \mathrm{~mm}$ Bole dianeter -32.7 Plete porectity $=40 \%$

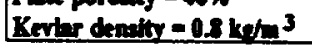

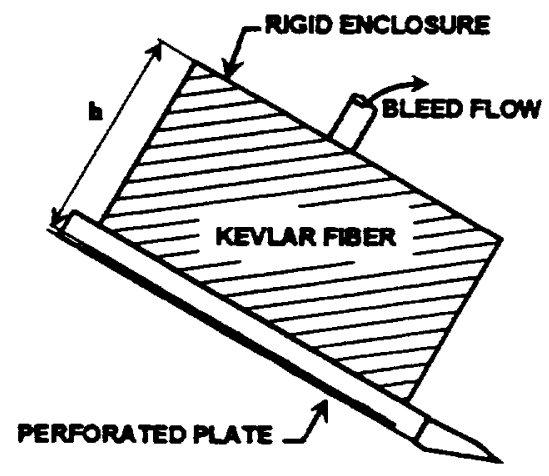

Fig. 3 Upper wall acoustic treatment

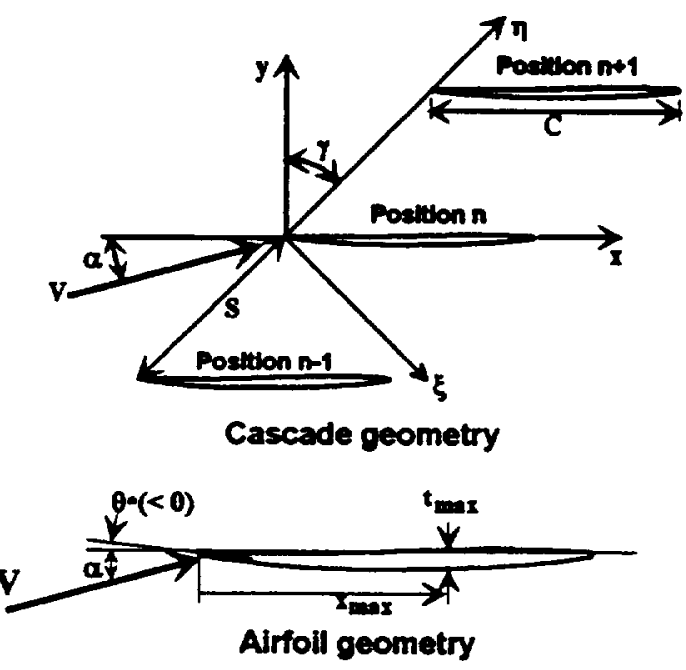

Fig. 4 Airfoil and cascade geometry

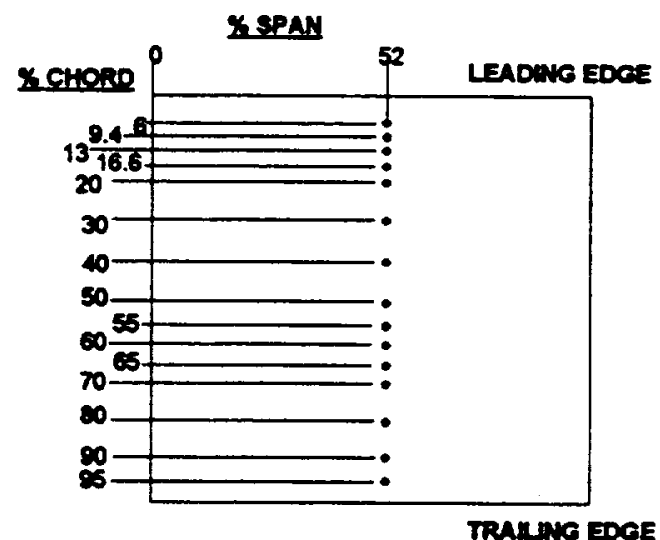

(a) Midspan taps

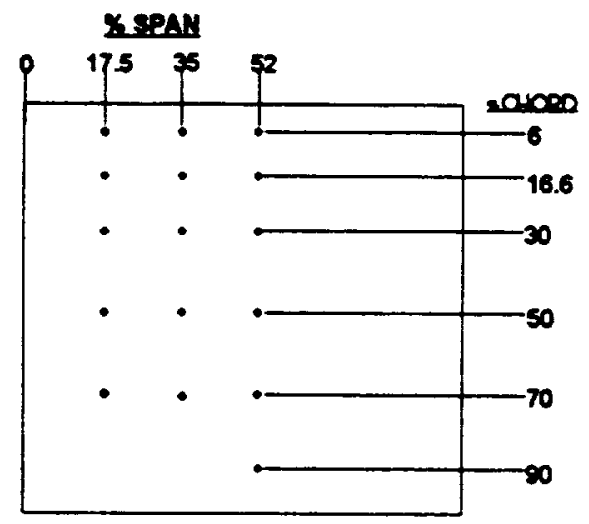

(b) Spanwise and redundant taps

Fig. 5 Airfoil surface pressure taps 


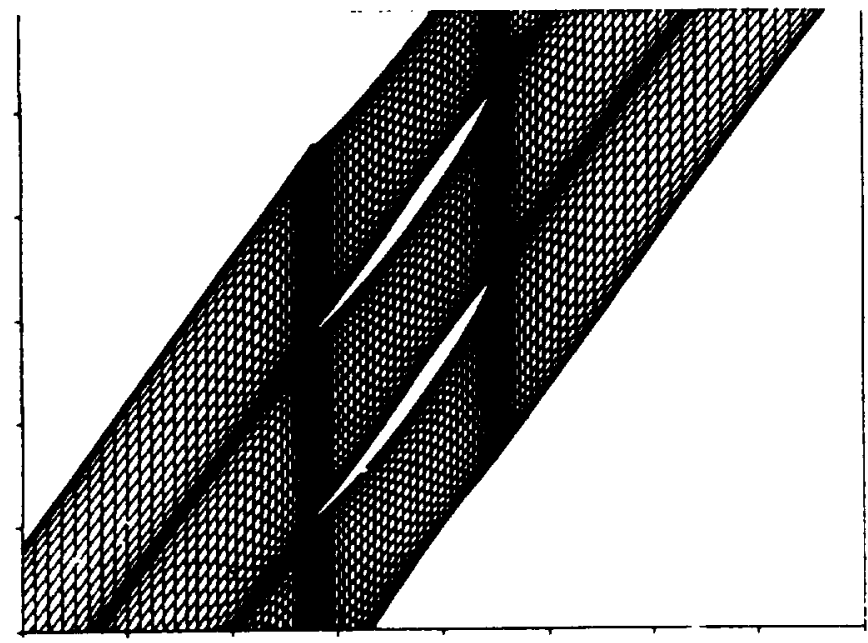

Fig. 6 SFLOW/LINFLO Grid

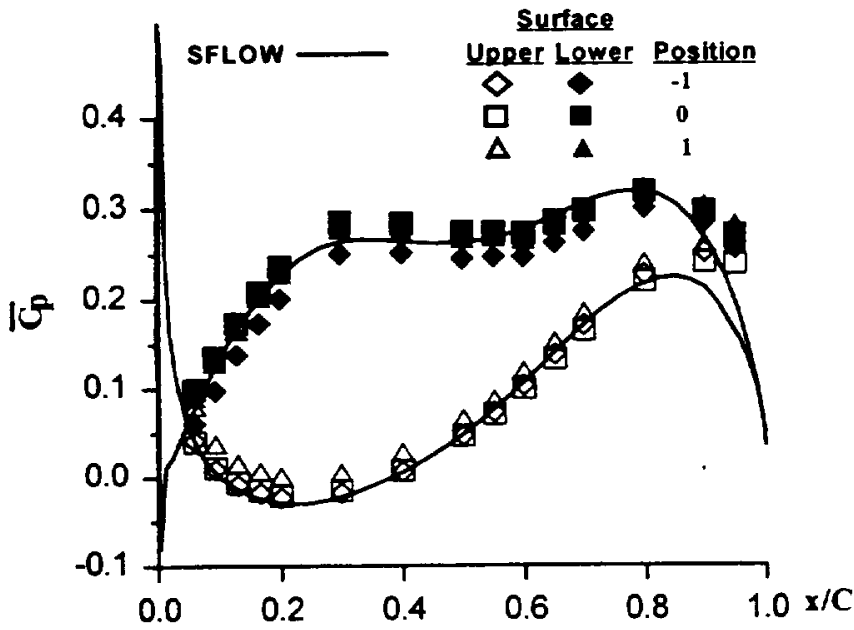

Fig. 7 Airfoil surface pressure coefficient distribution, $M=0.5, \alpha=0^{\circ}$

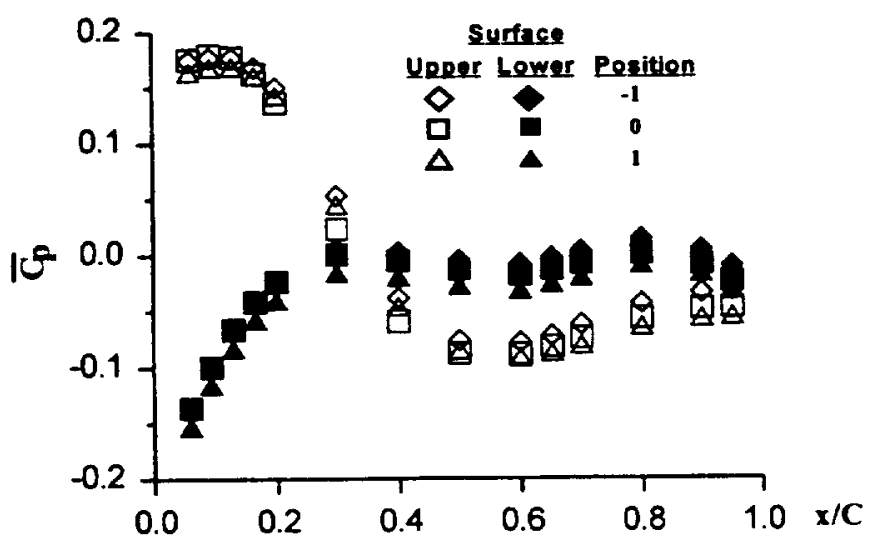

Fis. 8 Airfoil surface pressure coefficient distribution, $M=0.5, \alpha=10^{\circ}$

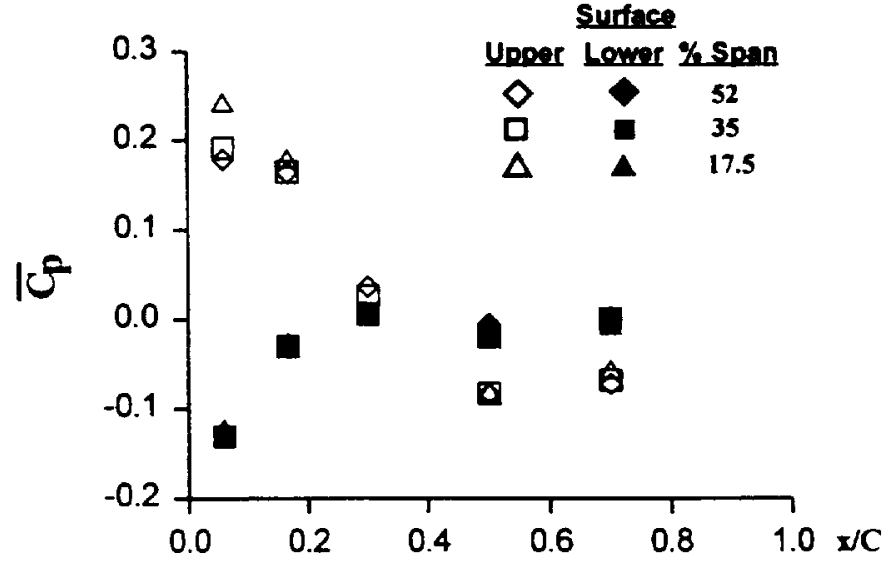

Fig. 9 Spanwise variation of airfoil surface pressure coefficient distribution, $\mathrm{M}=0.5, \alpha=10^{\circ}$

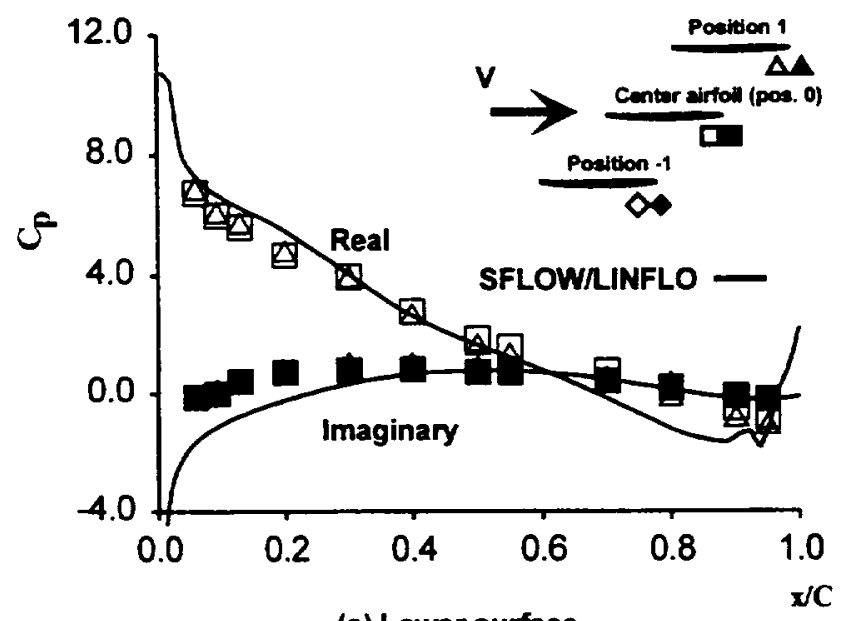

(a) Lower surface

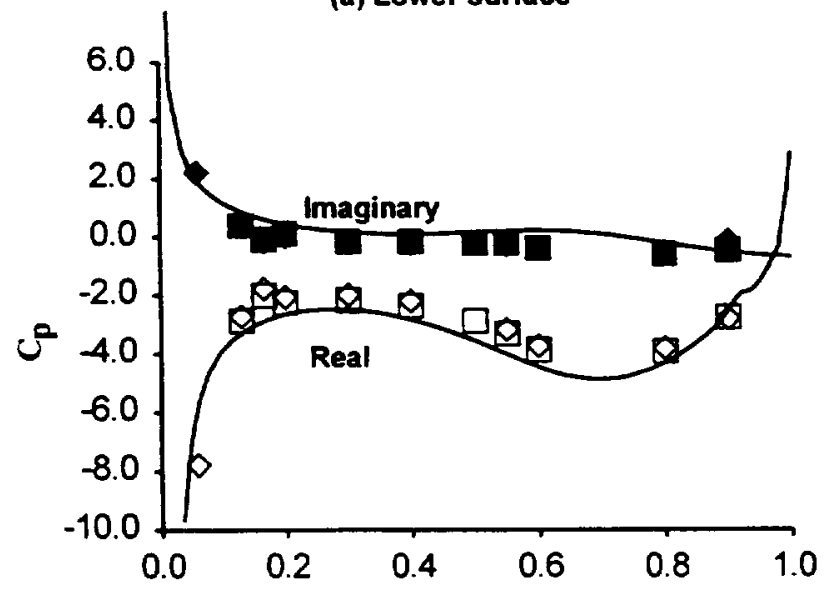

(b) Upper surface $\quad$ I/C

Fig. 10 First harmonic airfoil surface pressure coefficients, $M=0.5, \alpha=0^{\circ}, \beta=180^{\circ}, k=0.8$ 


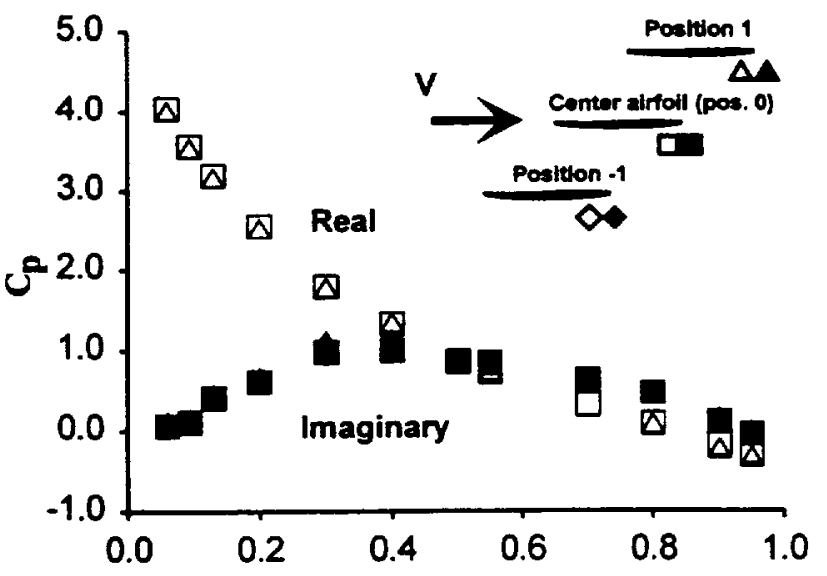

(a) Lower surface $\quad x / C$

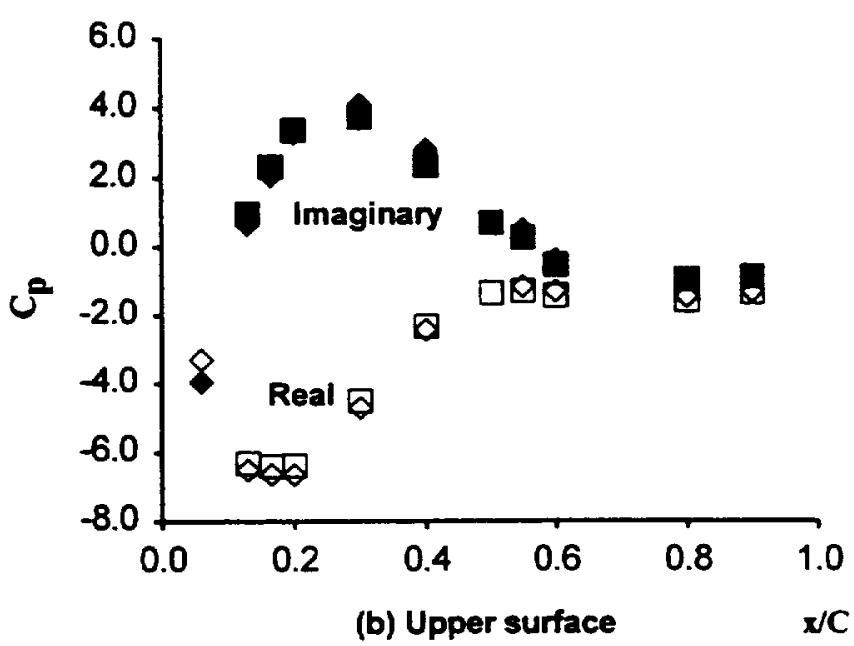

Fig. 11 First harmonic airfoil surface pressure coefficients, $M=0.5, \alpha=10^{\circ}, \beta=180^{\circ}, k=0.8$

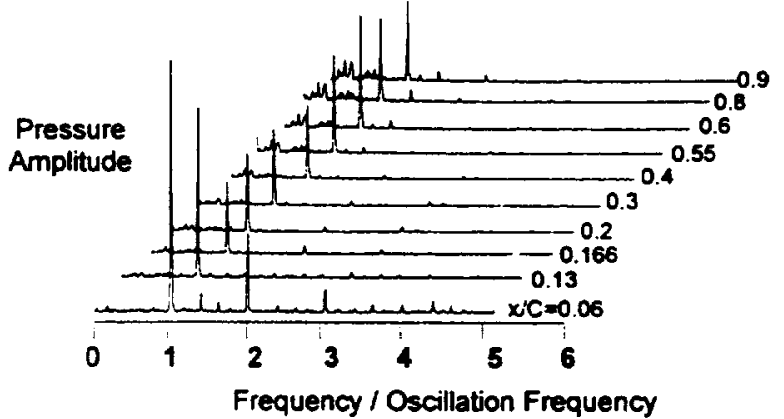

(a) $\alpha=0^{\circ}$

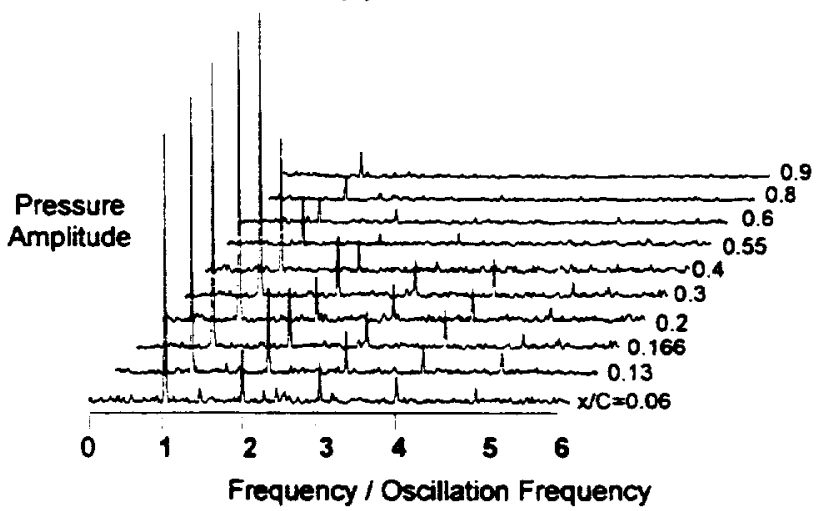

(b) $\alpha=10^{\circ}$

Fig. 12 Airfoil upper surface pressure spectra, $M=0.5$, $\beta=180^{\circ}, k=0.8$

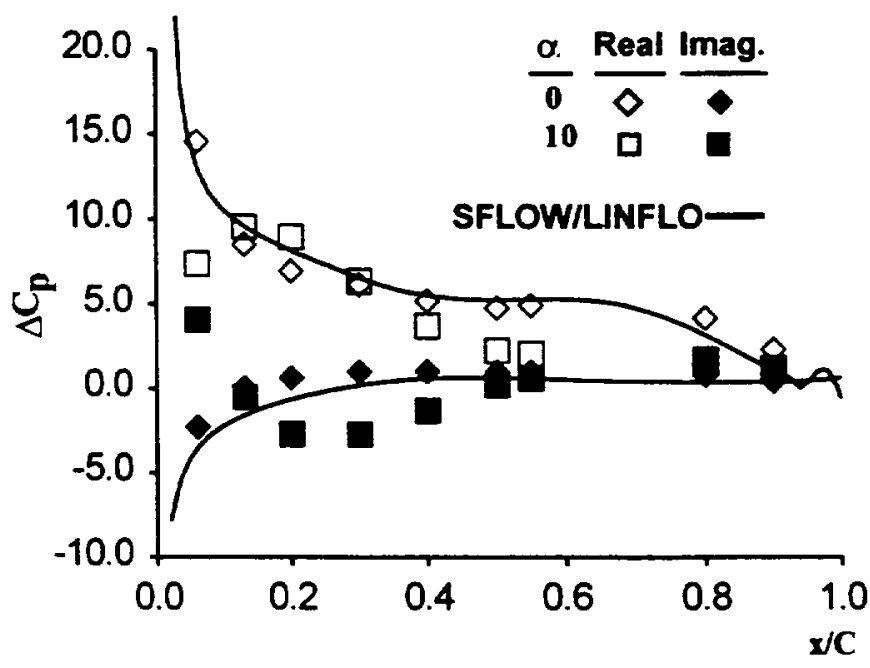

Fig. 13 Unsteady pressure difference coefficient distribution, $M=0.5, \beta=180^{\circ}, k=0.8$ 

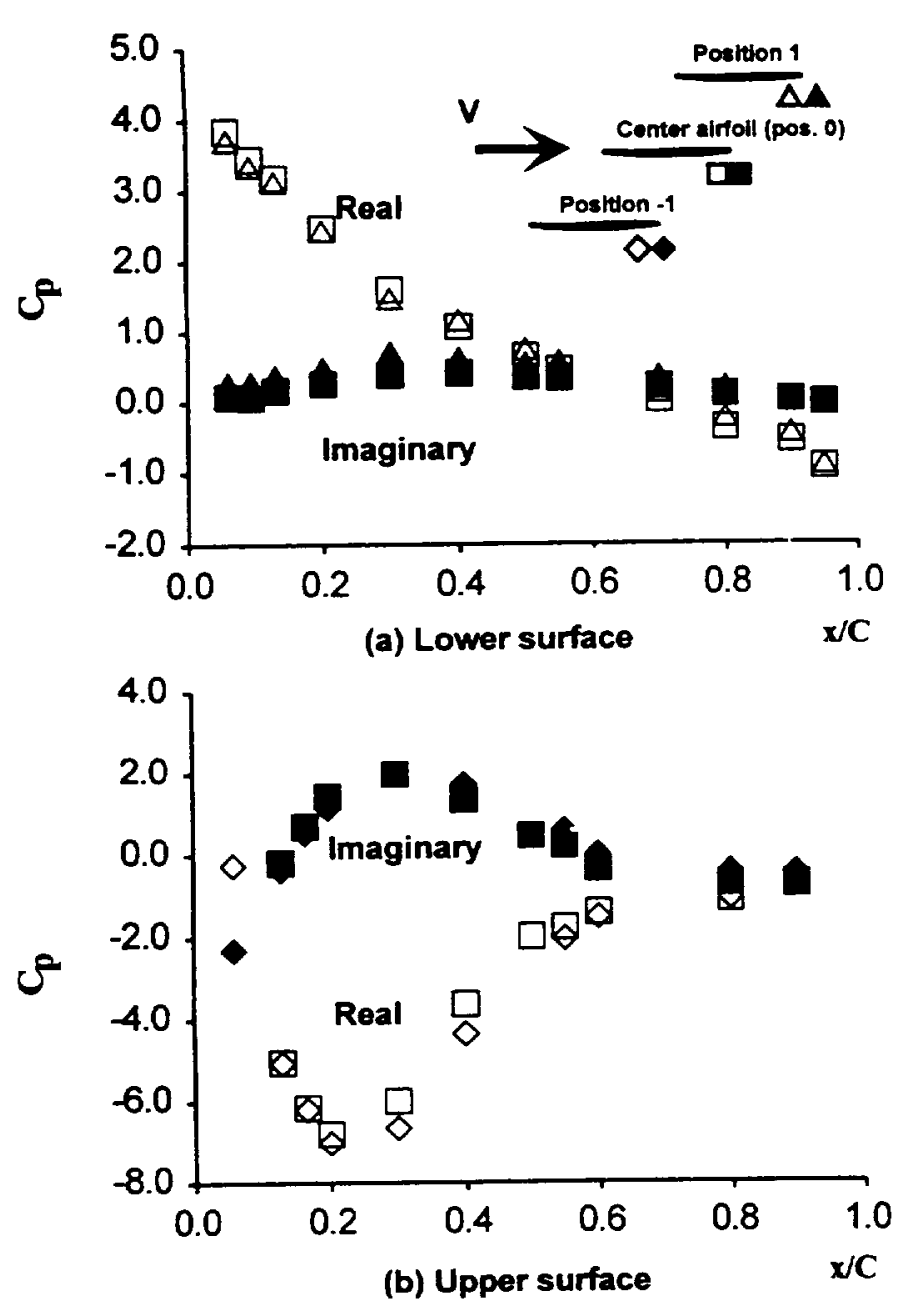

Fig. 14 First harmonic airfoil surface pressure coefficients, $M=0.5, \alpha=10^{\circ}, \beta=180^{\circ}, k=0.4$

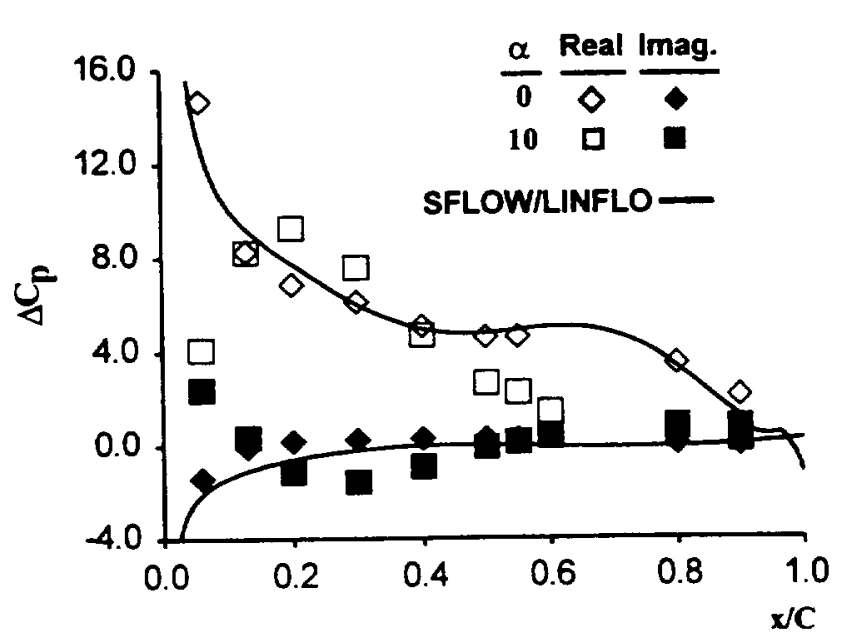

Fig. 15 Unsteady pressure difference coefficient distribution, $\mathrm{M}=0.5, \beta=180^{\circ}, \mathrm{k}=0.4$
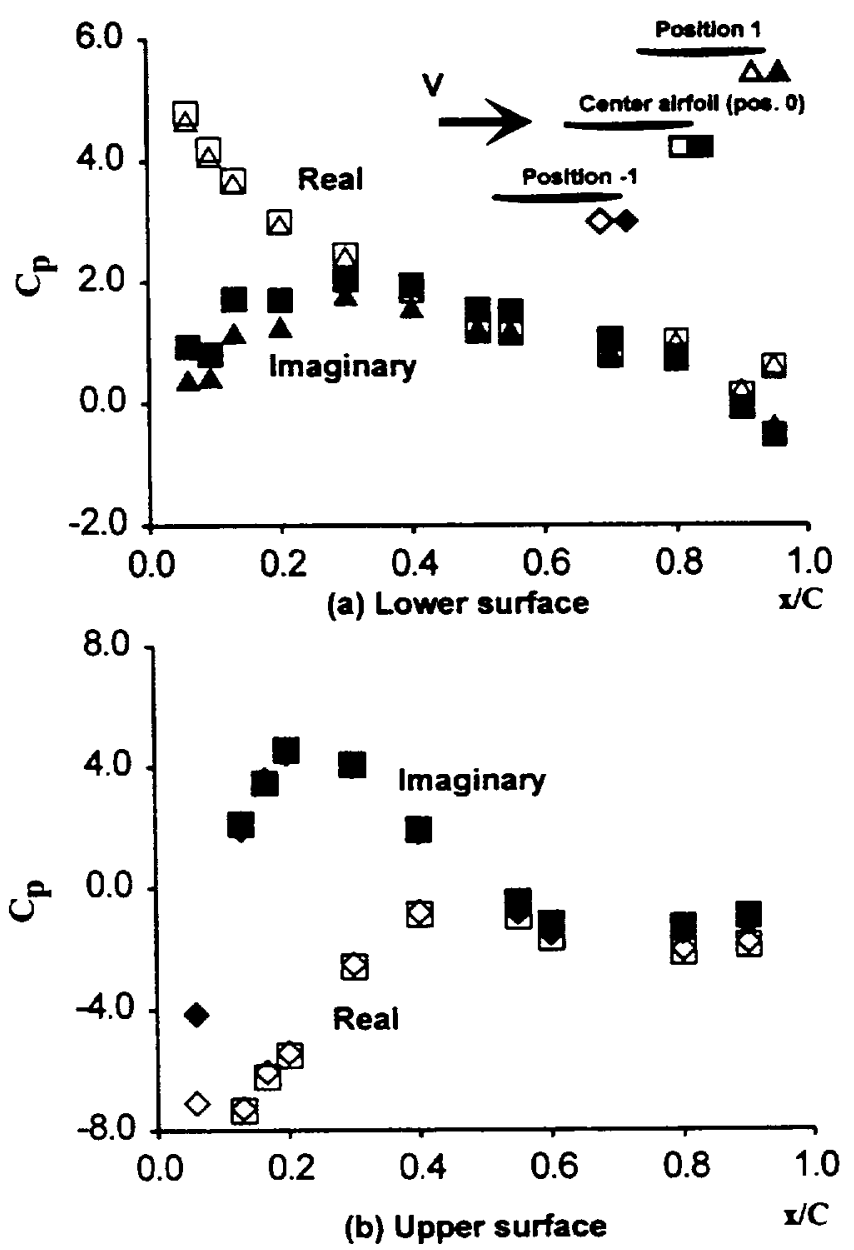

Fig. 16 First harmonic airfoil surface pressure coefficients, $M=0.5, \alpha=10^{\circ}, \beta=180^{\circ}, k=1.2$

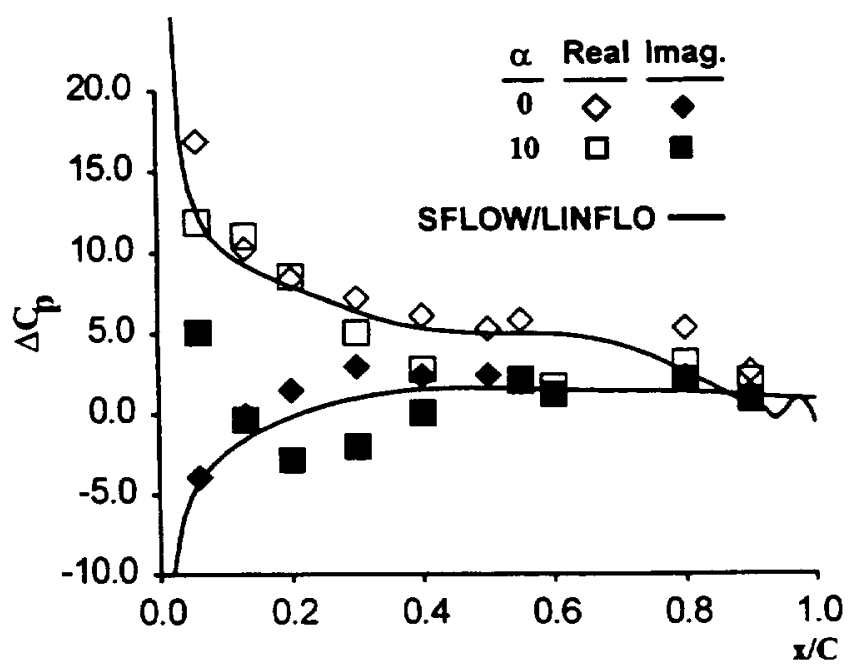

Fig. 17 Unsteady pressure difference coefficient distribution, $M=0.5, \beta=180^{\circ}, k=1.2$ 

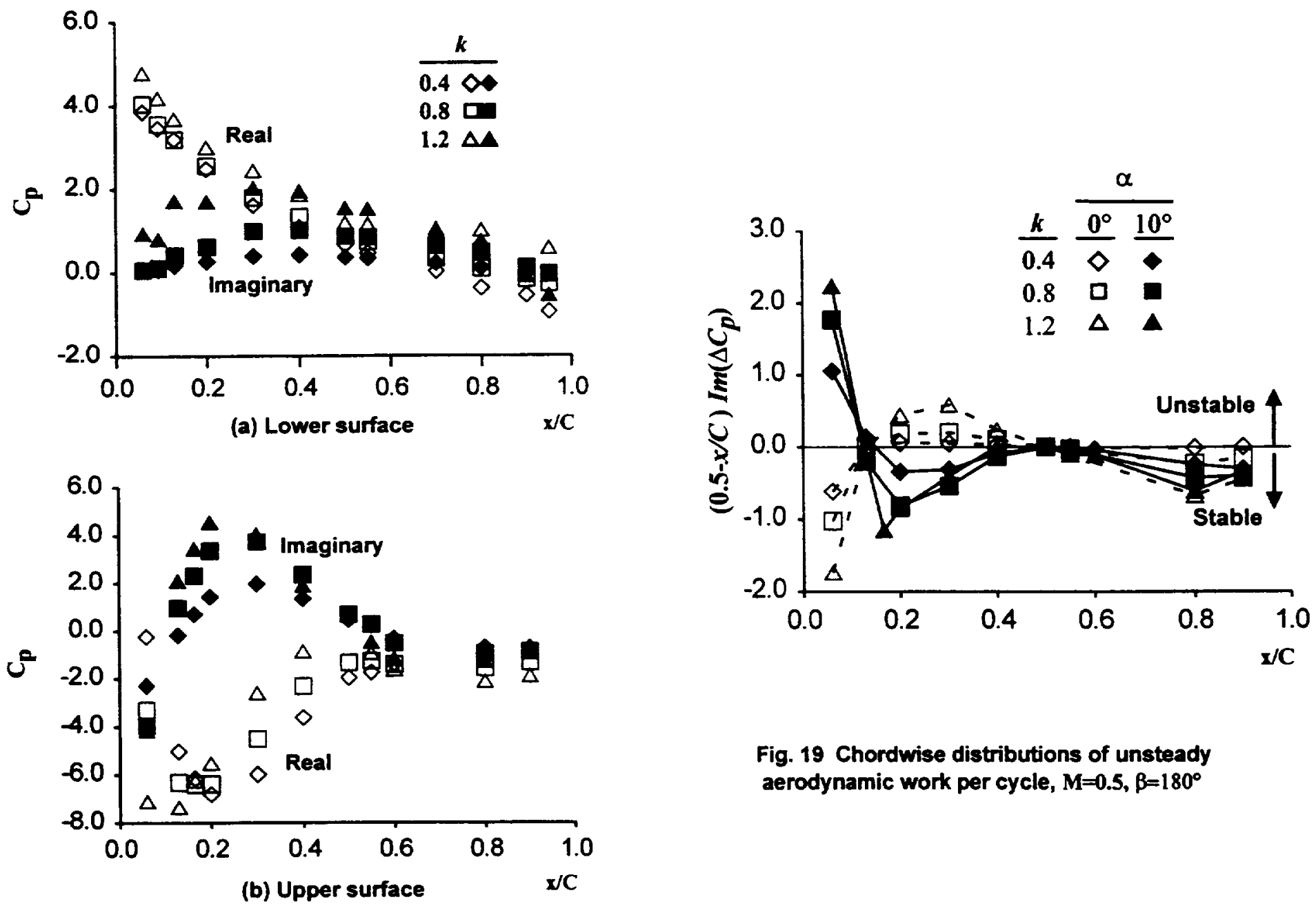

Fig. 18 First harmonic airfoil surface pressure coefficients, $M=0.5, \alpha=10^{\circ}, \beta=180^{\circ}$ 



\begin{tabular}{|c|c|c|c|c|}
\hline \multicolumn{3}{|c|}{ REPORT DOCUMENTATION PAGE } & & $\begin{array}{l}\text { Form Approved } \\
\text { OMB No. 0704-0188 }\end{array}$ \\
\hline \multicolumn{5}{|c|}{ 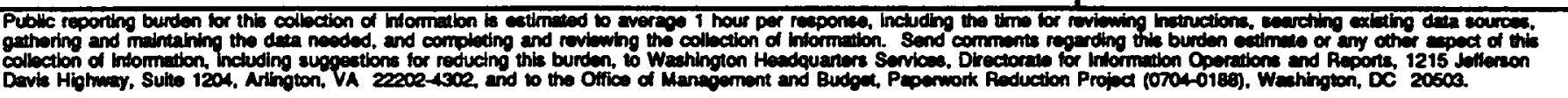 } \\
\hline 1. AGENCY USE ONLY (Leave blank) & $\begin{array}{l}\text { 2. REPOPT DATE } \\
\text { June } 1996\end{array}$ & \multicolumn{3}{|c|}{$\begin{array}{l}\text { 3. REPOAT TYPE AND DATES COVERED } \\
\text { Technical Memorandum }\end{array}$} \\
\hline \multicolumn{3}{|c|}{$\begin{array}{l}\text { 4. TILE AND SUBTIIL } \\
\text { Oscillating Cascade Aerodynamics at Large Mean Incidence }\end{array}$} & \multicolumn{2}{|c|}{ 5. FUNDING NUMBERS } \\
\hline \multicolumn{3}{|l|}{ 6. AUTHOR(S) } & \multicolumn{2}{|c|}{ WU-505-62-10 } \\
\hline \multicolumn{3}{|c|}{$\begin{array}{l}\text { 7. PERFOAMNG OAGANZZATION NAME(S) AND ADDRESS(ES) } \\
\text { National Aeronautics and Space Administration } \\
\text { Lewis Research Center } \\
\text { Cleveland, Ohio } 44135-3191\end{array}$} & \multicolumn{2}{|c|}{$\begin{array}{l}\text { 8. PERFOANANG OAGANIZATION } \\
\text { REPOAT NUMBER }\end{array}$} \\
\hline \multicolumn{3}{|c|}{ 9. SPONSORANGMONTORUNG AGENCY MAME(S) AND ADDRESS(ES) } & \multicolumn{2}{|c|}{$\begin{array}{l}\text { 10. SPONSORINGMONTOPING } \\
\text { AGENCY REPORT NUMBER } \\
\text { NASA TM-107247 }\end{array}$} \\
\hline \multicolumn{5}{|c|}{$\begin{array}{l}\text { 11. SUPPLEMENTARY NOTES } \\
\text { Prepared for the 41st Gas Turbine and Aeroengine Congress sponsored by the International Gas Turbine Institute of the American } \\
\text { Society of Mechanical Engineers, Birmingham, United Kingdom, June 10-13, 1996. Daniel H. Buffum, NASA Lewis Research Center, } \\
\text { Vincent R. Cappece and Aaron J. King, Department of Mechanical \& Aeronautical Engineering. University of Califomia, Davis, Califor- } \\
\text { nia 95616; Yehia M. EL-Aini, Pratt \& Whitney, West Palm Beach, Florida. Responsible person, Daniel H. Buffum, organization code } \\
\text { 2760, (216) 433-3759. }\end{array}$} \\
\hline \multicolumn{4}{|c|}{$\begin{array}{l}\text { 12a. DISTRABUTIONAVALABILTY STATENENT } \\
\text { Unclassified - Unlimited } \\
\text { Subject Category } 07 \\
\text { This publication is available from the NASA Center for AeroSpace Information, (301) 621-0390. }\end{array}$} & TRIBUTIONCODE \\
\hline \multicolumn{5}{|c|}{$\begin{array}{l}\text { 13. ABSTRACT (Maximum } 200 \text { mords) } \\
\text { The aerodynamics of a cascade of airfoils oscillating in torsion about the midchord is investigated experimentally at a large } \\
\text { mean incidence angle and, for reference, at a low mean incidence angle. The airfoil section is representative of a modem, } \\
\text { low aspect ratio, fan blade tip section. Time-dependent airfoil surface pressure measurements were made for reduced } \\
\text { frequencies of up to } 1.2 \text { for out-of-phase oscillations at a Mach number of } 0.5 \text { and chordal incidence angles of } 0^{\circ} \text { and } 10^{\circ} \text {; } \\
\text { the Reynolds number was } 0.9 \times 10^{6} \text {. For the } 10^{\circ} \text { chordal incidence angle, a separation bubble formed at the leading edge of } \\
\text { the suction surface. The separated flow field was found to have a dramatic effect on the chordwise distribution of the } \\
\text { unsteady pressure. In this region, substantial deviations from the attached flow data were found with the deviations } \\
\text { becoming less apparent in the aft region of the airfoil for all reduced frequencies. In particular, near the leading edge the } \\
\text { separated flow had a strong destabilizing influence while the attached flow had a strong stabilizing influence. }\end{array}$} \\
\hline \multirow{2}{*}{\multicolumn{3}{|c|}{$\begin{array}{l}\text { 14. SUBJECT TERMS } \\
\text { Flutter, Unsteady aerodynamics; Oscillating cascade }\end{array}$}} & & $\begin{array}{l}\text { 15. NUIBER OF PAGES } \\
14\end{array}$ \\
\hline & & & & $\begin{array}{r}\text { 16. PAICE CODE } \\
\text { A03 }\end{array}$ \\
\hline $\begin{array}{l}\text { 17. SECURTYY CLASSIFICATION } \\
\text { OF REPORT } \\
\text { Unclassified }\end{array}$ & $\begin{array}{l}\text { 10. SECURTY CLASSIFICATION } \\
\text { OF THIS PAGE } \\
\text { Unclassified }\end{array}$ & 19. SEC & ITION & 20. LMUTATION OF ABSTRACT \\
\hline
\end{tabular}




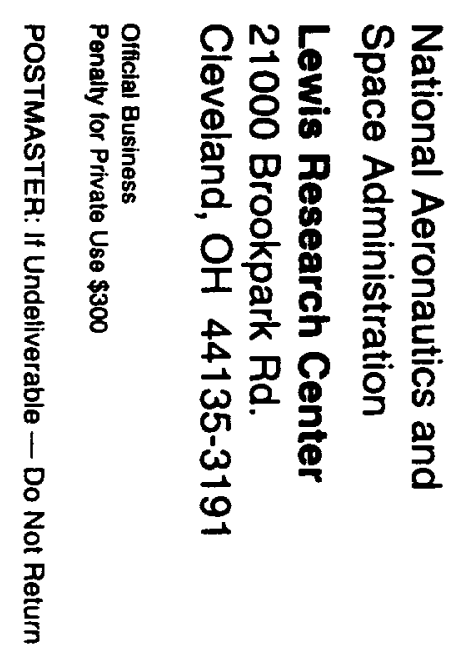

